\title{
The effects of mineral fertilizer and organic manure on soil microbial community and diversity
}

\author{
Wenhui Zhong • Ting Gu • Wei Wang • \\ Bin Zhang • Xiangui Lin • Qianru Huang • \\ Weishou Shen
}

Published online: 22 July 2009

(C) Springer Science + Business Media B.V. 2009

\section{Erratum to: Plant Soil \\ DOI 10.1007/s11104-009-9988-y}

The original article was inadvertently published with an inaccurate application rate of the composted pig manure. The correct application rate is shown here:

$\mathrm{N}, \mathrm{P}, \mathrm{K}$ and organic manure were applied in the form of urea $\left(120 \mathrm{~kg} \mathrm{~N}^{-1}\right.$ per year), calcium superphosphate $\left(60 \mathrm{~kg} \mathrm{P}_{2} \mathrm{O}_{5} \mathrm{ha}^{-1}\right.$ per year), $\mathrm{KCl}$ (120 kg K $\mathrm{K}_{2} \mathrm{O} \mathrm{ha}^{-1}$ per year), and composted pig manure (30 $\mathrm{t} \mathrm{ha}^{-1}$ per year), respectively.

Responsible Editor: Petra Marschner.

The online version of the original article can be found at doi:10.1007/s11104-009-9988-y.

W. Zhong $\cdot$ T. Gu $\cdot$ W. Shen $(\bowtie)$

College of Chemistry and Environmental Science,

Nanjing Normal University,

Nanjing 210097, China

e-mail: wsshen@njnu.edu.cn

W. Wang

College of Life Science, Nanjing Normal University,

Nanjing 210046, China

B. Zhang $\cdot$ X. Lin $\cdot$ W. Shen

State Key Laboratory of Soil and Sustainable Agriculture, Institute of Soil Science, Chinese Academy of Sciences,

Nanjing 210008, China

Q. Huang

Jiangxi Institute of Red Soil,

Jinxian, Jiangxi 331717 Nanchang, China 